\title{
The Lost Productivity Cost of Absenteeism Due to COVID-19 in Health Care Workers in Iran
}

\author{
Ahmad Faramarzi \\ Urmia University of Medical Sciences \\ Javad Javan-Noughabi ( $\sim$ javadjavan.n@gmail.com ) \\ Mashhad University of Medical Sciences \\ Seyed Saeed Tabatabaee \\ Mashhad University of Medical Sciences \\ Ali Asghar Najafpoor \\ Mashhad University of Medical Sciences \\ Aziz Rezapour \\ Iran University of Medical Sciences
}

\section{Research Article}

Keywords: Health Expenditures, Absenteeism, COVID-19, IRAN

Posted Date: July 27th, 2021

DOl: https://doi.org/10.21203/rs.3.rs-691798/v1

License: (c) (1) This work is licensed under a Creative Commons Attribution 4.0 International License. Read Full License 


\section{Abstract}

Background: Human resources management plays an important role in social development and economic growth. Absence from work due to health problems can make obstacles to the growth of economy. This study conducted aimed to evaluate the absenteeism in healthcare workers during the COVID-19 pandemic.

Methods: This cross-sectional study calculated the lost productivity cost of absenteeism among patients with COVID-19 between February 19, 2020, and September 21, 2020. The absenteeism costs were calculated using the human capital approach. Finally, we applied the linear regression to assess the impact of variables on the lost productivity of absenteeism due to COVID-19 on health care workers.

Results: The results of this study showed that there were 1958 patients with COVID-19 among the staff of Mashhad University of Medical Sciences (MUMS) from February to September 2020. The absenteeism days in our study were 32,209 days. Total costs due to absenteeism were estimated to be nearly $\$ 1.3$ million, with an average of $\$ 95.9$ per patient in a month. The results of regression model showed that gender, age, employment type, job, experience and monthly income had a significant impact on the cost of absenteeism due to COVID-19.

Conclusions: We calculated the absenteeism costs due to COVID-19 for the first time. Estimate costs and create evidence-based documentation can decrease the economic impacts of COVID-19 and improve human resources management during the COVID-19 pandemic.

\section{Introduction:}

In December 2019, a few pneumonia cases with unknown etiology were first reported in Wuhan city, Hubei Province, China [1]. One week later, it was discovered that the pathogen of this pneumonia belonged to the coronavirus family, and the World Health Organization (WHO) officially named it COVID19 on February 11, 2020 [2, 3]. The 2019 novel coronavirus disease (COVID-19) counts as the third outbreak caused by the coronavirus in the recent decades after Severe Acute Respiratory Syndrome (SARS) in 2002 and Middle East Respiratory Syndrome (MERS) in 2012 [4, 5]. SARS and MERS were not highly contagious compared to COVID-19. Overall, there were a total of more than 8,000 confirmed cases of SARS in about 29 countries and more than 2,000 cases of MERS across 27 countries $[4,6]$. While until December 3, 2020, COVID-19 has involved approximately 220 countries and more than 64 million people and has caused the death of about 1.5 million people [7].

Iran was one of the first countries that experienced the outbreak of COVID-19, and the first confirmed cases of COVID-19 in Iran were reported on February 19, 2020 [8]. COVID-19 has rapidly spread throughout Iran and until December 03, 2020, have been reported over 1 million confirmed cases of COVID-19 and about 49,000 deaths [7]. Therefore, the COVID-19 pandemic has become a global health concern, which has generated an unprecedented impact on all aspects of life, including economic conditions [9]. One of the main adverse economic consequences of a contagious disease, such 
as COVID-19, can be decreased productivity due to the absence of sick staff from work [10]. In terms of health economics, the lost productivity costs due to absence from work (also called absenteeism costs) are a significant component of the health care costs. A study conducted in the United States (US) in 2010 reported that chronic obstructive pulmonary disease (COPD) was responsible for 16.4 million days absence of work. This study estimated that the absenteeism cost of patients with COPD was \$3.9 billion [11]. Another study with 500 participants find that community-acquired pneumonia (CAP) causes 13 days of absenteeism [12]

There is a lack of information regarding the days' absence of work due to COVID-19 in the Iran. Therefore, this study has been conducted to evaluate the absenteeism costs of COVID-19 among the staff of Mashhad University of Medical Sciences (MUMS), located in Razavi Khorasan province in the northeast of Iran.

\section{Methods:}

\section{Study Design and participants}

We did a cross-sectional study to estimate the lost productivity cost of absenteeism due to COVID-19 among health care workers in the MUMS, located in Razavi Khorasan province in the northeast of Iran. According to data on Iran's Statistic Center, the Razavi Khorasan state had around 6.5 million people in 2018.

This study surveyed the patients with COVID-19 for 7-month, between February 19, 2020, and September 21,2020 . During this period, one thousand, nine hundred fifty-eight health care workers at MUMS were diagnosed with COVID-19 based on diagnostic criteria. We referred to the health information system in MUMS to study employee's medical records with COVID-19 to extract the required information. For this reason, gender, age, residence, workplace, marital status, employment type, kind of job, work experience, monthly salary, and the missed workday number for every employee were extracted.

\section{Estimate lost productivity cost}

We measured only the cost of productivity lost due to absence from work in the health department staff at MUSU, using the human capital approach. This approach is a method to calculate the indirect cost due to productivity loss. It is assumed the monetary value of losses productivity in the human capital approach, which can be caused by morbidity or premature death, is equivalent to the wage value in the absence of work [13]. Therefore, the period of absence from work due to illness is considered and valued by the achievable gross income.

We calculated the monetary value for a working day among employees who were absent due to COVID-19 and then multiplied by the number of missed workdays to estimate the absenteeism cost. We calculated the monetary value for a working day among employees who were absent due to COVID-19 and then 
multiplied by the number of missed workdays to estimate the absenteeism cost. The value monetary for a working day was computed using current salaries. All costs were converted into US dollars. The exchange rate used for conversion is 1 USD $=42,000$ Iranian Rials.

\section{Statistical Analysis}

We first assessed the disease distribution among participants based on sociodemographic variables (gender, age, residence, workplace, marital status, employment type, kind of job, and work experience). Then, we calculated the lost productivity cost of absenteeism due to COVID-19. The absenteeism costs are computed on a monthly and total. The mean, standard division, and percentage were used to describe costs according to variables. Besides, t-test and ANOVA were performed at a level significant of $5 \%$. Finally, we applied the linear regression to assess the impact of variables on the lost productivity of absenteeism due to COVID-19 on health care workers. The regression model followed as below;

$Y_{i}=a+\beta_{1} X_{1}+\beta_{2} X_{2}+\beta_{3} X_{3}+\beta_{4} X_{4}+\beta_{5} X_{5}+\beta_{6} X_{6}+\beta_{7} X_{7}+\beta_{8} X_{8}+\beta_{9} X_{9}+\beta_{10} X_{10}+\varepsilon_{i}$

In this model, $Y_{i}$ represents the dependent variable that is the total lost productivity cost of absenteeism for 7-month; $X_{1}$ and $X_{2}$ are gender and age, respectively; $X_{3}$ and $X_{4}$ represent the marital status and residence of participants; $X_{5}$ to $X_{8}$ are attributed to the patient's job characteristics, including the type of employment and job, workplace, and experience; $X_{9}$ is the natural logarithm of monthly income; $X_{10}$ is the missed workday number; $\beta$ is the vector of regression coefficients and shows the change in the total costs due to the change on independent variables; $\varepsilon_{i}$ is the error term.

All analyses were performed using Stata 14 (Stata Corp, College Station, Tex) software. Results were considered statistically significant if $p<0.05$.

\section{Results:}

Since the first reported case of COVID-19 in Iran to September 21, 2020, there were 1,958 cases in the health care workers at MUMS, of which 781 cases happened by men, and 1,177 occurred among women. Table 1 presents the sociodemographic characteristic for the patients with COVID-19 in the cohort study. The mean age of patients was approximately 40 -year, and more than $76 \%$ of patients aged over 30 -year. Employees with COVID-19 in the cohort were mostly married (69\%), 78\% of whom resided in Khorasan Razavi's capital, and more than 50\% were employed in hospitals with more than 200 beds. Among participants, $55 \%$ and $2.4 \%$ were nurses and physicians, respectively. One thousand nine hundred fiftyeight patients with COVID-19 in the health sectoral had created 32,209 absenteeism days. 
Table 1

The Sociodemographic for the patient with COVID-19

\begin{tabular}{|ll|}
\hline Variable & Number of patients (percent) \\
\hline Gender & $781(39.89)$ \\
Female & $1177(60.11)$ \\
\hline Age & $468(23.9)$ \\
$<30$ years & $970(49.54)$ \\
30 to 40 years & $415(21.2)$ \\
41 to 50 years & $105(5.36)$ \\
$>50$ years & 35.76 \\
Mean (years) & \\
\hline City of residence & $1531(78.19)$ \\
Mashhad & $427(21.81)$ \\
Other cities & \\
\hline Workplace & $669(34.17)$ \\
Small hospital (<200 bed) & $1118(57.1)$ \\
Large hospital (>200 bed) & $171(8.73)$ \\
Medical emergency & $1356(69.25)$ \\
\hline Marital status & $393(20.07)$ \\
Married & $209(10.67)$ \\
Single & \\
Other & $867(44.28)$ \\
\hline $\begin{array}{l}\text { Employment Type } \\
\text { Permeant }\end{array}$ & \\
Non-permanent & \\
\hline
\end{tabular}




\begin{tabular}{|ll|}
\hline Variable & Number of patients (percent) \\
\hline Job & $1077(55.01)$ \\
Nurse & $47(2.4)$ \\
Physician & $252(13.13)$ \\
Paramedic staff & $577(29.47)$ \\
Other staffs & \\
\hline Experience & $1007(51.43)$ \\
$<=8$ year & $799(40.81)$ \\
$>8$ year & $152(7.76)$ \\
Not available & 8.61 \\
Mean (years) & \\
\hline Number of missed work day & 32,209 \\
\hline
\end{tabular}

Table 2 shows the lost productivity cost due to absenteeism among patients with COVID-19 by the sociodemographic variables among the health care staff. Total costs due to absenteeism were estimated to be nearly $\$ 1.3$ million, with an average of $\$ 95.9$ per patient in a month. Males with $\$ 537.8$ thousand were responsible for $40.9 \%$ of the total costs, and the patients aged 30 to 40 -year old accounted for $47.9 \%$ of the total lost productivity cost due to absenteeism. Furthermore, total costs among married patients were almost 4-times that of single, while the average cost of absenteeism due to COVID-19 per month was estimated at $\$ 97$ and $\$ 90$ for a married and single patient, respectively. 
Table 2

The lost productivity cost due to absenteeism for the patient with COVID-19 by the sociodemographic variables

\begin{tabular}{|c|c|c|c|}
\hline Variable & $\begin{array}{l}\text { Cost per patient- month } \\
\text { (Mean } \pm \text { SD) }\end{array}$ & $\begin{array}{l}\text { Total cost } \\
\text { (\% total cost) }\end{array}$ & P-Value \\
\hline Gender & $98.4 \pm 29.6$ & $537,857(40.9)$ & 0.0017 \\
\hline Male & $94.3 \pm 27.6$ & $776,729(59.1)$ & \\
\hline \multicolumn{4}{|l|}{ Female } \\
\hline Age & $85.4 \pm 19.5$ & $279,715(21.3)$ & $<0.0001$ \\
\hline$<30$ years & $92.7 \pm 24.4$ & $629,600(47.9)$ & \\
\hline 30 to 40 years & $108 \pm 29.8$ & $313,649(23.8)$ & \\
\hline 41 to 50 years & $124.7 \pm 49.5$ & $91,621(7)$ & \\
\hline \multicolumn{4}{|l|}{$>50$ years } \\
\hline City of residence & $96.3 \pm 29.9$ & $1,032,405(78.5)$ & 0.2161 \\
\hline Mashhad & $94.4 \pm 22.6$ & $282,181(21.5)$ & \\
\hline \multicolumn{4}{|l|}{ Other cities } \\
\hline Workplace & $94.9 \pm 23.3$ & $444,267(33.8)$ & 0.31 \\
\hline Small hospital ( $<200$ bed $)$ & $96.8 \pm 32.9$ & $757,248(57.6)$ & \\
\hline Large hospital (> 200 bed) & $94.5 \pm 8.3$ & $113,071(8.6)$ & \\
\hline \multicolumn{4}{|l|}{ Medical emergency } \\
\hline Marital status & $97.4 \pm 30.2$ & $924,842(70.4)$ & $<0.0001$ \\
\hline Married & $90.1 \pm 27.2$ & $247,920(18.9)$ & \\
\hline Single & $96.9 \pm 14.1$ & $141,824(10.7)$ & \\
\hline \multicolumn{4}{|l|}{ Other } \\
\hline Employment Type & $108 \pm 30$ & $655,660(49.9)$ & $<0.0001$ \\
\hline Permanent & $86.3 \pm 23$ & $658,926(50.1)$ & \\
\hline Non-permanent & & & \\
\hline
\end{tabular}




\begin{tabular}{|llll|}
\hline Variable & $\begin{array}{l}\text { Cost per patient- month } \\
\text { (Mean } \pm \text { SD) }\end{array}$ & $\begin{array}{l}\text { Total cost } \\
\text { (\% total cost) }\end{array}$ & P-Value \\
\hline Job & $99.1 \pm 27.6$ & $747,260(56.8)$ & $<0.0001$ \\
Nurse & $118.2 \pm 25.8$ & $38,894(3)$ & \\
Physician & $100.1 \pm 30.9$ & $180,092(13.7)$ & \\
Paramedic staff & $86.2 \pm 26.3$ & $348,339(26.5)$ & \\
Other staffs & & & - \\
\hline All patients & $95.9 \pm 28.5$ & $1,314,586$ & - \\
\hline
\end{tabular}

Nurse and physician staff accounted for approximately $57 \%$ and $3 \%$ of total costs, respectively. However, the lost productivity cost due to absenteeism in terms of the average for physicians was higher than for nurses (\$118 vs $\$ 99$ ). The cost of lost productivity due to absenteeism in the health care workers with COVID-19 has significant differences based on gender, age, marital status, employment type, and job.

The regression model results are presented in Table 3. The model results revealed that the variable of gender, age, employment type, job, experience, monthly income, and the number of missed workdays were significant predictors. More than $97 \%$ of change by the lost productivity cost of absenteeism due to COVID-19 associated with the included variable. Men faced absenteeism costs on average \$3.53 more than women. Employees over the age of 50-year have, on average, about $\$ 36$ more in lost productivity costs than employees under the age of 30 , while these costs were lower for employees aged 30 to 50 years compared to the age group less than 30 years. Moreover, a percent increase in monthly income was associated with an average of $\$ 783$ increase in the cost of lost productivity. A missed workday resulted in a cost of $\$ 37$ in the health sector. 
Table 3

The regression model of determining factors on the lost productivity cost in patients with COVID-19

\begin{tabular}{|c|c|c|}
\hline Variable & Coefficient (Cl \%95) & p-value \\
\hline Gender & Ref. & 0.04 \\
\hline Male & $-3.53(-6.95,-0.11)$ & \\
\hline \multicolumn{3}{|l|}{ Female } \\
\hline Age & Ref. & 0.16 \\
\hline$<30$ years & $-3.17(-7.59,1.25)$ & 0.4 \\
\hline 30 to 40 years & $-2.39(-8.06,3.26)$ & $<0.0001$ \\
\hline 41 to 50 years & $35.72(27.71,43.73)$ & \\
\hline \multicolumn{3}{|l|}{$>50$ years } \\
\hline City of residence & Ref. & 0.17 \\
\hline Mashhad & $-3.62(-8.8,1.56)$ & \\
\hline \multicolumn{3}{|l|}{ Other cities } \\
\hline Workplace & Ref. & 0.44 \\
\hline Small hospital (< 200 bed) & $1.75(-2.74,6.26)$ & 0.56 \\
\hline Large hospital (> 200 bed) & $4.57(-10.81,19.96)$ & \\
\hline \multicolumn{3}{|l|}{ Medical emergency } \\
\hline Marital status & Ref. & 0.15 \\
\hline Single & $-2.98(-7.1,1.12)$ & 0.03 \\
\hline Married & $-10.13(-19.64,-0.62)$ & \\
\hline \multicolumn{3}{|l|}{ Other } \\
\hline Employment Type & Ref. & $<0.0001$ \\
\hline Permanent & $14.25(9.82,18.67)$ & \\
\hline \multicolumn{3}{|l|}{ Non-permanent } \\
\hline Job & Ref. & 0.007 \\
\hline Nurse & $-14(-24.14,-3.87)$ & 0.44 \\
\hline Physician & $1.77(-2.82,6.36)$ & $<0.0001$ \\
\hline Paramedic staff & $16.16(11.66,20.67)$ & \\
\hline Other staffs & & \\
\hline
\end{tabular}




\begin{tabular}{|lll|}
\hline Variable & Coefficient $(\mathrm{Cl}$ \%95) & p-value \\
\hline Experience & Ref. & $<0.0001$ \\
$<=8$ year & $-8.21(-12.4,-4.03)$ & $<0.0001$ \\
$>8$ year & $-39.01(-58.19,-19.83)$ & \\
Not available & & \\
\hline Monthly income (Logarithm) & $783.11(771.31-794.91)$ & $<0.0001$ \\
\hline Number of missed work day & $37.45(37.06,37.84)$ & $<0.0001$ \\
\hline Constant & $-5508.99(-5595.81,-5422.17)$ & $<0.0001$ \\
\hline Number of observations & 1958 & \\
$\mathrm{R}^{2}$ & 0.9728 & \\
$\mathrm{R}^{2}$ adjusted & 0.9726 & \\
$\mathrm{~F}$ & 4086 & \\
\hline
\end{tabular}

\section{Discussion:}

To our knowledge, this is the first analysis to provide estimates of the absenteeism costs of COVID-19 among health care workers of Mashhad University of Medical Sciences. Our study found 1,958 healthcare workers with covid-19 between 20 February 2020 and 21 September 2020, with a total absenteeism cost of $\$ 1.3$ million. Our study showed that patients with COVID-19 created 32,209 days absence of work. COVID-19 is a highly transmissible virus that is transmitted through respiratory droplets from sneezing or coughing. COVID-19 can lead to different symptoms, from mild symptoms such as fever, cough and sore throat, to severe symptoms such as pneumonia, acute respiratory distress syndrome, kidney failure, and death [14]. Therefore, quarantine and social distancing are essential for controlling COVID-19 disease epidemic.

As a result of the COVID-19 lockdown and social distancing policies, a significant negative shock is imposed on the world economy. For example, in China, the COVID-19 caused economic losses of $13.5 \%$ in its industrial production, $21 \%$ in retail sales, $92 \%$ in car sales, and $95 \%$ in restaurants [15]. These economic losses have led to an unimaginable increase in unemployment. In the first five months of the COVID-19 pandemic, it is estimated that the decline in working hours was equivalent to two hundred million full-time job loss [16]. The COVID-19 also has led to increased absenteeism in the workplace. A report on trends in absenteeism during March and April 2020 shown that the COVID-19 causes a significant increase in days absence of work among healthcare personnel and production workers such as meat, poultry, and fish processing workers [17]. It is claimed that seasonal influenza can lead to 11,100 days absence of work annually [18]. Golicki et al. in a study aimed to estimate the indirect costs of pneumococcal diseases in Poland in 2017, concluded that pneumonia was responsible for approximately 
81000 days of sick Leaves annually [19]. Wyrwich et al. in a study of symptom burden and time for recovery from community-acquired pneumonia among 500 participants reported that CAP causes 13 days of absenteeism [12]. A study in the United States reported that chronic obstructive pulmonary disease (COPD) created 16.4 million days absence of work in 2010 [11].

Our study showed that the total costs of absenteeism due to COVID-19 were about \$1.3 million. Also, the average per patient monthly absenteeism costs were $\$ 95.9$. It is showed that infectious disease could have significant economic impacts through reduced productivity, loss of life, business closures, trade disruption, and decimation of the tourism industry [20].

As far as we know, no study was carried out to evaluate the absenteeism costs of COVID-19. Ford et al. calculated the absenteeism costs of COPD among American adults in 2010. In this study, the lost productivity costs due to absence from work were about $\$ 3.9$ billion [11]. In a study conducted by Gianino et al, the total cost of absenteeism due to seasonal influenza outbreaks among health care workers was 1.7 million euros annually. Also, the average absenteeism cost due to seasonal influenza was 327 euros per person [18].

We found that the variable of gender, age, employment type, job, experience and monthly income had a significant impact on the cost of lost productivity due to absenteeism in the health care workers with COVID-19. In our study, the major shares of total cost were related to female, nurses, married and 30-40 years old workers. In a similar study on seasonal influenza, Gianino et al. reported that nurses and allied health professionals and workers in the 40-49 age range were responsible for the most absenteeism costs due to seasonal influenza [18]. Also, several studies showed that rates of absence are related to socioeconomic status [21]. Kim et al in a study aimed to determine the absenteeism of financial stress showed that there are a positive and significant relationship between income and absenteeism [21]. In this study, the variables including age and gender did not relate to absenteeism [21]. A reason for differences in results may be related to differences in the diseases under study.

Clark et al. reported that formal and informal education was negatively related to absenteeism [22].

\section{Conclusion:}

To our knowledge, our analyses provide the first estimates of absenteeism costs due to COVID-19. Absenteeism creates higher costs, reduced productivity, and can lead to increased indiscipline among employees. Estimate costs and create evidence-based documentation can decrease the economic impacts of COVID-19 and improve the human resources management during the COVID-19 pandemic.

\section{Declarations}

\section{Acknowledgements}


The present article was adopted from the proposal number 990978 that was supported by Mashhad University of Medical Sciences.

\section{Authors' contributions:}

JJN was responsible for the conceptual design of the study, analysis, drafting the first version of the article and finalization of the article. AF was responsible for the data analysis and drafting the first version of the article. SST were involved in the data collection. All authors read and approved the final manuscript.

\section{Funding:}

No funding was received for this research.

\section{Competing interests:}

The authors declare that they have no Competing interests.

\section{Availability of data and materials:}

All data are available on reasonable request.

\section{Ethics approval and consent to participate:}

Ethical approval for this study was obtained from Ethics Committee of the Mashhad University of Medical Sciences [The code of Ethics: IR.MUMS.REC.1400.001]. The analysis was performed using secondary data from the health information system in MUMS. Agreement to access the health information system in MUMS was obtained according to proposal number 990978 that was approved by MUMS and ethical approval. All methods were carried out per relevant guidelines and regulations.

\section{Consent for publication:}

Consent for publication is not applicable as this study did not include names, images, or videos relating to individual participants.

\section{References}


1. committee WMHCJWMHCWCh: Report of clustering pneumonia of unknown etiology in Wuhan City. 2019.

2. Organization WH: Naming the coronavirus disease (COVID-19) and the virus that causes it. In.; 2020.

3. Zhu N, Zhang D, Wang W, Li X, Yang B, Song J, Zhao X, Huang B, Shi W, Lu RJNEJoM: A novel coronavirus from patients with pneumonia in China, 2019. 2020.

4. Organization WH: Consensus document on the epidemiology of severe acute respiratory syndrome (SARS). In.: World Health Organization; 2003.

5. Nassar M, Bakhrebah M, Meo S, Alsuabeyl M, Zaher WJERMPS: Middle East Respiratory Syndrome Coronavirus (MERS-CoV) infection: epidemiology, pathogenesis and clinical characteristics. 2018, 22(15):4956-4961.

6. Organization WH: Middle East respiratory syndrome coronavirus (MERS-CoV). 2019. In.; 2016.

7. COVID-19 Coronavirus Pandemic [https://

8. Coronavirus disease 2019 (COVID-19) Situation Report - 31 [https://www.who.int/docs/defaultsource/coronaviruse/situation-reports/20200220-sitrep-31-covid-19.pdf?sfvrsn=dfd11d24_2]

9. Anderson RM, Heesterbeek H, Klinkenberg D, Hollingsworth TDJTL: How will country-based mitigation measures influence the course of the COVID-19 epidemic? 2020, 395(10228):931-934.

10. Cetron M, Landwirth J: Public health and ethical considerations in planning for quarantine. The Yale journal of biology and medicine 2005, 78(5):329.

11. Ford ES, Murphy LB, Khavjou O, Giles WH, Holt JB, Croft JB: Total and state-specific medical and absenteeism costs of COPD among adults aged 18 years in the United States for 2010 and projections through 2020. Chest 2015, 147(1):31-45.

12. Wyrwich $\mathrm{KW}, \mathrm{Yu} \mathrm{H}$, Sato R, Powers $\mathrm{JH}$ : Observational longitudinal study of symptom burden and time for recovery from community-acquired pneumonia reported by older adults surveyed nationwide using the CAP Burden of Illness Questionnaire. Patient related outcome measures 2015, 6:215.

13. Warren JL, Yabroff KR, Meekins A, Topor M, Lamont EB, Brown ML: Evaluation of trends in the cost of initial cancer treatment. Journal of the National Cancer Institute 2008, 100(12):888-897.

14. Li Q, Guan X, Wu P, Wang X, Zhou L, Tong Y, Ren R, Leung KS, Lau EH, Wong JY: Early transmission dynamics in Wuhan, China, of novel coronavirus-infected pneumonia. New England journal of medicine 2020.

15. McKee $M$, Stuckler $D$ : If the world fails to protect the economy, COVID-19 will damage health not just now but also in the future. Nature Medicine 2020, 26(5):640-642.

16. Van Lancker W, Parolin Z: COVID-19, school closures, and child poverty: a social crisis in the making. The Lancet Public Health 2020, 5(5):e243-e244.

17. Groenewold MR, Burrer SL, Ahmed F, Uzicanin A, Free H, Luckhaupt SE: Increases in health-related workplace absenteeism among workers in essential critical infrastructure occupations during the covid-19 pandemic-United States, March-April 2020. Morbidity and Mortality Weekly Report 2020, 69(27):853. 
18. Gianino MM, Politano G, Scarmozzino A, Stillo M, Amprino V, Di Carlo S, Benso A, Zotti CM: Cost of sickness absenteeism during seasonal influenza outbreaks of medium intensity among health care workers. International journal of environmental research and public health 2019, 16(5):747.

19. Golicki D, Dobrowolska I, Gora A, Jaśkowiak K, Niewada M: Indirect costs of pneumococcal diseases in Poland: an analysis based on absenteeism data from Social Insurance Institution. sepsis (A40-41) 2018, 2:G05.

20. Pak A, Adegboye OA, Adekunle Al, Rahman KM, McBryde ES, Eisen DP: Economic consequences of the COVID-19 outbreak: the need for epidemic preparedness. Frontiers in public health 2020, 8.

21. Kim J, Garman ET: Financial stress and absenteeism: An empirically derived model. Financial Counseling and Planning 2003, 14(1):31-42.

22. Clark AE, Oswald AJ: Satisfaction and comparison income. Journal of public economics 1996, 61(3):359-381. 